\title{
A Corpus-Based Study on the Differences of Chinese and American Online English Sports News Headlines from the Perspective of Cross-Cultural Communication
}

\author{
Wenhua $\mathrm{Hu}^{1} \&$ Mei Guo ${ }^{2}$ \\ ${ }^{1}$ School of Foreign Languages, Dalian University of Technology, Dalian, China \\ ${ }^{2}$ School of Foreign Languages, Dalian University of Technology, Dalian, China \\ Correspondence: Wenhua Hu, School of Foreign Languages, Dalian University of Technology, Dalian, China. \\ E-mail: hwh68@aliyun.com
}

\author{
Received: July 31, 2013 Accepted: August 23, 2013 Online Published: September 24, 2013 \\ doi:10.5539/ijel.v3n5p87 URL: http://dx.doi.org/10.5539/ijel.v3n5p87
}

This paper is supported by the Fundamental Research Funds for the Central Universities (DUT13RW412); Teaching Reform Funds of Dalian University of Technology (MS201314); Program of Social and Scientific Planning Fund of Liaoning Province (L12DYY028); Program of Dalian Academy of Social Science (2012dlskyb079).

\begin{abstract}
The present study generalizes the features of online American sports news headlines through the corpus and compares them with the English sports news headlines written by Chinese journalists, aiming to provide some references for the Chinese official websites to help reader better understand the content and therefore improve English skills. The present study first reviews the relevant theories on news headlines and then establishes a corpus with 248 headlines by collecting 10 days' (1 Feb. $2013 \sim 10$ Feb. 2013) sports news headlines from the Xinhua and Yahoo website. After finding the Yahoo online English sports news headlines' characteristics in lexicology, grammar and rhetoric, the author at last searches the disparities in English headlines written by Chinese due to the different thinking models, language skills and culture of sports, and provides some suggestions for improvement from the perspective of cross-cultural communication.
\end{abstract}

Keywords: sports English, news headlines, corpus, cross-cultural communication

\section{Introduction}

Nowadays, the online news has been an increasing important source for people to know the current information because of its efficiency, abundance and convenience. With the trend of globalization, the Chinese network media has translated a quantity of foreign news into Chinese, among which a majority of news is about China, and it becomes an important channel for China to publicize itself better. The six main Chinese governmental English media websites include english.peopledaily.com, china.org.cn, chinadaily.com, and english.cri.cn. The sports news account for approximately $25 \%$ among these websites, which became the vital plate to show Chinese comprehensive national strength. However, due to the negative transference of mother tongue and the deficiency of professional English sports talents, the "chinglish" is unavoidable for Chinese sports journalists to write English news, which greatly reduces the reading interests of foreign readers, and influences the Chinese publicity to the outside world. Furthermore, there is a few number of studies on news writing in English for Chinese. So, this paper takes the news' eye - the headline as the object of study. News headline is not only as important as news content, but also very difficult for journalist to write in genuine and typical English idiomaticity, which has features of concision, colloquialism, and allusion. This paper takes the English headlines on the same type of network media - Chinese Xinhua and American Yahoo as study materials, establishing two small corpuses respectively with headlines depicted in the same period (1 Feb. $2013 \sim 10 \mathrm{Feb}$. 2013). The present study analyzes the characteristics of the two webs and contrasts the differences between them based on the samples in the corpuses, finding the advantages and disadvantages of Chinese online sports English news headlines and providing some suggestions. The purpose of this paper for sports English majors is to help them to comprehend the combination of sports and English and to use their professional skills into social works because the aim of 
media is to make Chinese sports English news more western and to attract more foreigners to familiarize themselves with Chinese sports and China.

This paper contains 4 parts. Firstly, it explains the functions of the news headlines and stresses the special functions of the online English sports news headlines by using the explicit samples in the corpuses to illustrate. Secondly, the paper summarizes the characteristics of headlines in the corpuses in lexical, grammatical and rhetorical aspects (Zhang, 2004). Thirdly, the present study contrasts the differences between Chinese and American online English sports news headlines and offers some references for Chinese sports English news' writing. At last, it analyzes the limits of this study on the whole, and provides suggestions for the future studies.

\section{Literature Review}

\subsection{Functions of the News Headlines}

The headlines are the eyes of the news, also the concentration of the whole content. The outstanding and eye-catching headlines determine the readers' further reading of the news directly. A result of the survey (Yang Lin 204) about headlines-reading shows that $94 \%$ people choose to read the content of the news after reading their headlines, and readers absorb $34 \%$ information from the headlines. The function of headlines is so crucial that it may encourage the readers to read on. (Liu, 2002). Meanwhile, Chen Hongmei (2005, p. 104) said that headline-news is also popular. In this era of information explosion, the selective reading is necessary for browsers to save the precious time to catch the points of news. People expect to know the central content of stories, some distinctive or fresh points about news and attitudes of certain media especially the official and authoritative one through the headlines. Thus, the basic functions of headlines should be the following. At first, the headlines can unveil the principal contents and demonstrate the values of news in short words rather than the long and large ones; Secondly, it could state the news comments and express the attitudes of media with unique and clear-cut stands; Thirdly, it should attract the readers by flexible changing. Here is a sample from the corpuses to illustrate the above-mentioned functions.

\section{Ibra to Miss Juve Clash}

(Xinhuanet. English sports 2013. 2. 7)

The concision and clarity should be the first impression when people scan this headline. We can know the "who" - "Ibra" and "what" - "miss clash" through only 19 letters in 5 words, which state the most valuable information that the soccer fans are concerned about. This headline uses the abbreviations "Ibra" and "Juve" to respectively stand for the world's top striker Zlatan Ibrahimovic in AC Milan and the league leaders Juventus. Meanwhile, it uses two short words "miss" and "clash" to represent the meaning of sidelining and competition. These short words clearly imply that AC Milan will fight with Juventus and the top striker Ibra will be sidelined. Furthermore, if readers tasted the word "miss" carefully, they can realize the sympathetic or sorry attitude of sportswriters. However, some readers may begin to be curious about the "why", if they did not know the three-match ban from Swedish international. Appropriate elimination of some less important elements could arouse the curiosity of readers and push them to read more of following parts.

Some more examples for reference:

\section{Adrian Peterson's Jersey Rant}

(Yahoo Sports 1 Feb. 2013)

Flamengo and Botafogo Draw

(Xinhuanet. English sports 6 Feb. 2013)

The first example utilizes the rhetoric device of personification to show the jersey's anger instead of Adrian himself, which makes readers laugh easily. Likewise, the second one uses the rhyme smartly and musically to arouse the reading appetite.

\subsection{Functions of Online English Sports News Headlines}

Obviously, online English sports news headlines contain the basic functions of news headlines. However, sports news has its own special functions due to its internet platform and sports contents. Online news is much quicker than the traditional media, even being issued in seconds after the stories happening and people can search the old news timelessly by entering the key words or date. Also, without the limitation of paper, online news has much larger capacity than that of newspapers and people do not need to consider tidying up a large quantity of old newspapers. In addition, sports news is different from other sorts of news, which is dynamic, competitive and suspenseful corresponding to the features of sports. Thus, online sports news' own special functions should 
demonstrate the sports style vividly. Firstly, it can highlight the real-time of the sports events - people read news like events happening simultaneously. Secondly, it can show the dynamic of sports - readers feel excited as watching the live competition. Thirdly, the headlines can stress the entertainment of sports - readers feel relaxed and pressure-released. The Following example from the corpus will explain these special functions in details.

\section{Austin Rivers' Buzzer-Beater Adds to Duke-UNC Lore}

(Yahoo! Sports 9 Feb, 2013 1:59 am EST)

The "buzzer-beater" must be the readers' first impression after reading the headline. Without doubt, it's the "what" in this headline, which means Austin River got the last scoring at buzzer. "Buzzer-beater" not only uses the professional idiom of basketball, but also the rhetoric device of alliteration, which makes the phrase or sentence read rhythmically and sound musical. Thus, besides clarifying the main point of the story, the headline shows the intensive atmosphere of the match scene by "buzzer", which makes people imagine as if the referee put the button of buzzer at the time 00:00, meanwhile readers see the Austin Rivers shot the ball into the basket by "beater". The whole headline draws a vivid picture of the last moment on the basketball court filled with excitement, intension, and competitiveness of athletics. And "lore" gives the highly comment on Austin Rivers, Duke and this event, which gives the fans an expecting result and a well relaxing after intensive waiting. The upload time implies that the journalists must have stayed up late for the watching match, recording and uploading on the website.

Below are more examples for reference:

'Star power’ Boosts Kentucky

(11:55 pm EST Yahoo Sports)

Preseason Ranks: Designated Hitter

(7:30 pm EST Yahoo Sports)

“Star Power” is called “明星效应” in Chinese, which illustrates the free creation circumstance of internet platform. All kinds of "ranks" belong to a significant type of online news because of ranks' dynamic change and enormousness.

\section{Discussion}

\subsection{Characteristics of American Online English Sports News Headlines}

Generally speaking, English sports headlines have the features of terseness, conspicuousness, compactness and humor. The present paper analyzes and summarizes the characteristics of online English sports news headlines from lexical, grammatical, rhetorical and structural aspects in the following part, based on the corpuses including 186 headlines from Yahoo Sports website during the 1 Feb. 2013 to 10 Feb. 2013 and 62 headlines from Xinhua English sports website.

\subsection{Lexical Characteristics of American Online Sports News Headlines}

Lexical difference is the first obvious impression on readers. The words used in headlines look shorter, fresher and easier than the rest of the written news.

\subsubsection{Short Words Are Preferred}

(1) Abbreviation and Digit

Due to the specialty of sports, news relate to many complicated names of teams, organizations, athletes, nations and a large number of scores., Using the words of abbreviations and digits is one of the most important ways to express the maximum volume of information in the smallest space, and the real-time characteristic of sports. The common abbreviated words in sports like NBA, CBA and NFL are popular, however, some others may be only known by fans in certain kinds of sports. This paper gives examples from the corpus to explain this phenomenon in details in the following part.

Reds Like What They See in Weakened NL Central

Ranking of Current Super Bowl-Winning QBs

All About the ACC: Finally, It's Time for Duke-Carolina

Tynes Was Ready To Kick Winning FG But Strategy Intervenes

Full names of the underlined abbreviations:

NL: (baseball) National League 


\section{QB: Quarter Back}

ACC: Atlantic Coast Conference Basketball teams

FG: Field Goal

According to these examples, abbreviations in sports news not only relate to names of organizations, athletes and federations, but also to professional names of some specific motions. Here is a List of some more common abbreviations in sports for reference:

OG: Olympic Games

MLB: Major League Baseball

UEFA: Union of European Football Association

FIFA: Fédération Internationale de Football Association

UEFA: Union of European Football Association

IBF: International Badminton Federation

ESPN: Entertainment and Sports Programming Network

(2) Short Nouns and Verbs

It is a good way to show the dynamic and competitiveness of sports besides saving space by using short words, especially the verbs, which even seldom appear in written form but in spoken one. The following examples are used to explain the worth of midget words in details:

Nick Diaz's Straightforward Fight Approach Defies Crazy Portrayal (challenges)

Latest Chapter of Lakers-Celtics Rivalry Nears End (closes to)

Chauncey Billups Vows to Return From Injury (declare)

It is obvious that the alternative words in parentheses are much more common and formal than the original ones, which are not only the demand of vividness, but also typesetting and wider readership.

(3) Vogue Words

The internet is the fastest platform to convey the latest information. The well-known activity - "annual online hot words" has become one of expecting things. Without doubt, some may spring from sports news. Some common words today are also newly created before. New words in sports are mainly created by compounding, shifting meaning and borrowing from other languages:

'Star Power' Boosts Kentucky

Cheesesteak King Tony Luke Drops 128 Pounds

The words "star power" and "cheesesteak" respectively use the way of shifting meaning and compounding and they have the same character that look simple but make readers a little bit confused about their meaning. So it is easy to understand the journalists' intention - future reading. Another feature of this kind of new words is easy to remember after scanning only once.

\subsubsection{Conversion of Parts of Speech}

In order to have a better expressive effect, conversing the parts of speech is an attractive and flexible way, corresponding right to the uncertain feature of sports. The following examples give more specific conversion:

Win or Lose, Ozzie Guillen's Marlins will entertain (loss)

Different from "win", the "lose" could not be used as noun, but this sentence converses verb into noun for adding the competitiveness without bringing any misunderstanding to audience.

\subsection{Grammar Characteristics of American Online Sports News Headlines}

\subsubsection{Non-Finite Verbs}

Instead of using the formal predicate, headlines utilize abundant non-finite verbs in forms of "to do" and "doing" to describe the events that will happen and are proceeding. Take the following samples to demonstrate:

Clemson-South Carolina Football Game To Become Mandatory By State Law?

Larry Bird Moving Down Celtics Scoring List

The words "to become" and "moving" do not cause any misunderstanding but express the different tenses in a 
simple, clear and new way.

\subsubsection{Omission of Words}

The omission is the most common phenomena in headlines to reduce the length directly. The omitted words often include articles, propositions, the verb "be" and conjunctions, which seldom arouse misunderstandings. The following samples from the corpus are meant to illustrate:

Jerry Sloan's Resignation (is) Still a Surprise to Jazz

Giants Fullback (is) an Unlikely Super Bowl Hero

Nick Diaz (is) Tested Positive for Marijuana After His UFC 143 Loss to Carlos Condit

As the cases shown above, in terms of content, verb "is" is not a necessary word to the sentences, because it is added by readers in the mind naturally when they are reading. Omitting functional words is a useful way to save space.

\subsubsection{Sentences Structure}

Punctuation occupies least space than any other words to condense the headlines. They mainly contain punctuation "," as the word "and", utilizing ":" instead of "say" or "be" and taking "?" as interrogative words.

Leafs, Wings \& the 2013 Winter Classic: Big House, big crowd, big fun

In this sentence, the colon ":" represents the verb "mean", "stand for" or some other similar ones, which not only save the several types but also look clear and lucid.

\subsection{Rhetorical Characteristics of American Online Sports News Headlines}

Rhetorical devices greatly increase the literary value both in visual and acoustic beauties. However, it is also a difficult requirement for journalists to write like literati. After analyzing the samples in the corpus of Yahoo, a variety of practical rhetorical devices are found in the headlines to make expressions like word pictures. Some common rhetoric examples from the corpus are listed below, and the names of rhetoric in the parentheses are noted by the author.

Red Sox Pinch Pennies After Beer-Soaked Collapse (alliteration)

Ryan Smyth's Trade Deadline Dilemma (alliteration)

Super Bowl Ad Flashback: “Apple's 1984” (metonymy)

Steelers' Brett Keisel Shaves Off NFL's Best Beard (metonymy)

Tim Tebow “Quite Taken” With TV Host (pun)

Kyle Stanley Gets Redemption, Unloads the 'Baton of Pain' on Spencer Levin (pun)

Adrian Peterson's Jersey Rant (personification)

True Patriots Love: How New England's Beloved NFL Team Got Its Name (personification)

The rhetoric devices above are common and useful in the headlines. Alliterations make headlines musical, metonymies arouse recreations and curiosity, puns make sentences beautiful and neat, and personifications express humor and creativity.

\section{Comparisons between Chinese and American Online English Sports News Headlines}

This chapter focuses on finding and analyzing the differences between Xinhua English sports news headlines and Yahoo's after the comparisons, based on the functions of sports news headlines, and the characteristics of American online sports news headlines. The differences are mainly analyzed in the angles of semantics, lexicology, and rhetoric, and the author discusses and provides some suggestive revisions.

\subsection{Semantic Differences}

Semantically speaking, headlines on Xinhua go much more straight to the results of the events, and have fewer narratives about the news' element of "how" than that of the Yahoo, which is totally different from the Chinese traditional beliefs that Chinese are accustomed to expressing or handling with things indirectly. However, the Chinese journalists' brief and direct descriptions do not save any spaces on the contrary they spoil the reading interest and curiosity of readers. There are too much more specific and basic introductions about elements of "who" and "what" in the information of headlines. The following examples from the corpus of Xinhua English news are used to explain this disadvantage.

Vasco da Gama's Young Player Dies on Field 


\section{Chinese Skater Liu Wins Silver at ISU}

\section{WC Canadian Olivier Jean Wins Men's 500m at ISU World Cup Short Track}

The cases above underline the elements of "who", "what" and "where". It is obvious that a few verbs are left after picking up the underlined parts. If sportswriters informed the names of players directly, headlines would bring more questions and curiosity to readers. It would be better if changed the "Vasco da Gama's young player" into player's name, which shows the respect to the athletes as well. Similarly, "Chinese skater Liu" is so basic that dwarfs his popularity. Equally, it needs not describe the basic information about the competition like ISU in the third example.

These kinds of headlines have weaker function of attracting readers to go on reading essays but have stronger effect of attracting more amateur sports fans to know the basic information about sports. Without doubt, Xinhua certainly wants to attract more readers no matter professional or amateur and their further reading of the essays. However, the inadequate attraction of Chinese English news headlines is not the problem of journal writing but the flexible application of English skills. Sportswriters need to combine the proficient English writing and abundant sports knowledge together, which just matches the skills of sports English majors. Thus, according to the summaries of linguistic characteristics of American online sports news headlines in the third part, some more comparisons and suggestive revisions about Chinese ones in lexicology, grammar, and rhetoric are given below.

\subsection{Lexical Differences}

As for Xinhua English headlines, there are data and statistics to show the results of competitions and abbreviations of federations, organizations and events, but the names' abbreviations of Chinese famous athletes as "Liu Xiang" and "Li Na" are seldom used. Since they are famous enough and some related information in the headline for reference, the "Liu" and "Li" are much better just like "Yao", which will not make foreign readers confused or tired of Chinese "Pin yin".

When it comes to the short nouns and verbs in Xinhua English sports news headlines, there are no problems with length of words but the choice and variety of those midget words. The problem is over Chinese journalists choosing formal, written and static words instead of spoken and living ones. So, it influences the effect of stimulating the reading interests by showing the tension and rivalry of sports. Some suggestive reversions in the parentheses are given after every example:

Li Na Withdraws From Paris Opener with Sore Back (quit/ out of)

Bielsa Delighted as Athletic Reach Spanish Cup Final (get)

Houston to Host 2013 NBA All-Star Game (announce)

Juventus Beat AC Milan in First Leg of Coppa Italia Semifinals (foils)

The short and oral words in the brackets are more similar with the customs of US news, which chooses more persuasive, dynamic and daily ones. There is no vogue word in the Xinhua corpus, which implies that Chinese journalists try to avoid unnecessary mistakes by not creating new words. Out of the same season, the conversion of parts of speech is rare in Xinhua English news headlines, in order to make the sentences lexically correct.

\subsection{Grammatical Differences}

As second language learners, it is difficult for Chinese to accept using non-finite verbs as predicates, omitting functional words, or taking punctuations as conjunctions or verbs in the sentences, which is the most obvious difference from American in order to write the grammatically right sentences. The author gives some advisable corrections in the parenthesis modeling the common non-finite patterns on Yahoo after every sample from the Xinhua corpus:

London is Ready to Host a Memorable Games, says Olympic Legends (omit "is")

Milan Sure Ibra Could Play Against Juve (to)

Sevilla Sack Coach Marcelino (Marcelino sacked)

Ajax in Crisis After Defeat Against Utrecht (defeating)

The Short Season Still Strong, Yao Irreplaceable, Said NBA Chief

(NBA chief: The short season still strong, Yao irreplaceable)

The underlined words above occupy double spaces compared with the alternative versions. It is unnecessary to waste those spaces in order to obey the grammar, which could be used flexibly in the headlines to show US local English. 


\subsection{Rhetorical Differences}

English rhetorical devices are also difficult for Chinese sports news writers, however, the metonymy is naturally applied in using the names of countries, organizations, or teams standing for the members in them. While if journalists wanted to use alliteration, pun and personification successfully, they would have a big vocabulary, a good grasp of knowledge of the sports English, and proficient skills of English writing. The present paper attempts to rewrite some headlines on Xinhua by using rhetorical devices based around the 4-year's learning of sports English.

Saturday's Serie A Matches Postponed due to Cold Weather

(Saturday's Serie A Matches "Frozen" by Cold Weather) (Pun)

Napoli Coach Mazzarri Blames Referee for Mistakes

(Napoli Coach Mazzarri Charge Judge For Fault) (Assonance)

Ghanaian Soccer Star Joins AC Milan

(AC Milan Embrace Ghanaian Soccer Star) (Personification)

Africa's Best Ekiring Promises to Win Badminton Title

(Africa's Best Ekiring Vows to Win Badminton Title) (Alliteration)

Rhetorical devices are difficult but we can make it after hard working as rewriting examples show above. The plain narratives become picturesque words in pun, assonance, personification and alliteration.

\section{Conclusion}

In general, the results show the big differences of headlines between Xinhua and Yahoo beyond the author's previous assumption because of the important positions of Xinhua, sports and headlines. The shortage of professionals who are good at both sports English and news writing would be one of the important reasons for Xinhua current situation. As the prevalence of English in the world and Chinese trend of learning English through the whole country, news written in western authentic English by Chinese journalists on the official websites is necessary, let alone the original taste of the news headlines. Sport is a global "lingua franca", rather than politics or economy filled with local features.

The present paper analyzes differences of online sports news headlines between Chinese and American in terms of semantics, lexicology, grammar and rhetoric and then provides some constructive revisions based on the summaries of characteristics of Yahoo, which stands for the American biggest online news platform. Certainly, the corrections are not the total negation of headlines on Xinhua, which should retain its advantages of being short, easy and clear. The corrections aim at polishing words and sentences 'structures in order to achieve the effect of rhetoric, entertainment and curiosity. The first step of summary of characteristics is the most important in the present paper. Thanks to the previous scholars who have done a lot of works on researching and summarizing the features of western news headlines, which serves for the further studies of translating English news headline into Chinese. However, an increasing number of foreign news especially the sports of both Chinese and English versions are mainly written by ourselves because of our big worldwide journalists team, their perfect language skills, and the boundlessness of sports.

The present paper not only benefits the Chinese sports English majors, journalists and governmental websites, but also provides useful findings for non-English speakers who are to take a good command of English. There are still a lot limits in this paper, and more studies about sports English need to be explored.

\section{References}

Anderson, D. A. (1998). Contemporary Sports Reporting. Chicago: Nelson Hall Publishers.

Cai, F.-T. (2007). Characteristics of online sports news headlines and translation strategy (Master's thesis). Shanghai university of Foreign studies, Shanghai.

Chen, H.-M. (2005). News editing. Wuhan: Publishing house of Wuhan University.

Li, Z.-X., \& Zhang, J. (1993). News English. Tianjin: Publishing house of Nankai University. http://dx.doi.org/10.1056/NEJM199312303292709

Liu, L. (2002). Discussion on News headlines. Beijing: Beijing social science publishing house.

Ma, J.-G. (2002). Review of English News paper. Beijing: Publishing House of Foreign Language Teaching and Research. 
Noonan, J. H., \& Mustain, G. (2007). Writings of News headlines. Shanghai: Publishing house of Fudan University.

Rao, M.-H. (2006). Perspective of Cross-culturual communication on sports news headlilnes (Mater's thesis). Fudan University, Shanghai.

Stapler, H. (1974). The Student Journalist and Sports Writing. NewYork: Richards Roson Press.

Stone, G. (1992). News writing. New York: Harper Collins Publishers.

Wilstein, S. (2002). Associated Press Sports Writing Handbook. New York: McGraw-Hill.

Zhang, J. (1994). The stylistic feature of online sports news headlines. Shanghai: Shanghai Foreign Language Education Publishing House.

Zhang, X.-F. (2009). Lexical features of online sports news headlines. Journal of Kaifeng university, 2009(4), 63-65.

\section{Copyrights}

Copyright for this article is retained by the author(s), with first publication rights granted to the journal.

This is an open-access article distributed under the terms and conditions of the Creative Commons Attribution license (http://creativecommons.org/licenses/by/3.0/). 